\title{
Brand Loyalty dan Pengaruhnya terhadap Keputusan Pembelian
}

Authors:

Marisi Butarbutar ${ }^{1}$

Efendi $^{2}$

Sudung Simatupang ${ }^{3}$

\section{Affiliation:}

1,2,3 Manajemen, Sekolah Tinggi Ilmu Ekonomi Sultan Agung, Pematangsiantar, Indonesia

Corresponding Author: Sudung Simatupang

Emails:

${ }^{1}$ marisibutarbutar84@gmail.co $\underline{\mathrm{m}}$

²efendi.wu@gmail.com

${ }^{3}$ selitaefraim@gmail.com

\section{Article History:}

Received: February 23, 2021

Revised : April 28, 2021

Accepted: May 28, 2021

How to cite this article: Butarbutar, M., Efendi., \& Simatupang, S. (2021). Brand loyalty dan pengaruhnya terhadap keputusan pembelian. Organum: Jurnal Saintifik Manajemen dan Akuntansi, 4(1), 40-54 doi:

https://doi.org/10.35138/organu $\underline{\text { m.v4i1.130 }}$

Journal Homepage: ejournal.winayamukti.ac.id/ind ex.php/Organum

\section{Copyright:}

(C) 2021. Published by Organum: Jurnal Saintifik Manajemen dan Akuntansi. Faculty of Economics and Business. Winaya Mukti University.
Abstract. One of the famous culinary industry brands in Pematangsiantar City is Toko Roti Ganda. The famous brand Of Toko Roti Ganda makes many visitors who have an impact on traffic jams. The phenomenon is due to the famous Toko Roti Ganda in the community makes the brand a top priority of the community compared to other brands for visitors who come. This study aims to determine the effect of brand loyalty on purchasing decisions at Toko Roti Ganda. This research was conducted on all residents of Pematangsiantar City and Simalungun Regency who have ever made purchases at the Roti Ganda. Furthermore, the results of respondents obtained from the study were 123 respondents. The research method was carried out by qualitative and quantitative. The results show that the research criteria are declared valid and reliable with the indicators met. For normality results that all research variables are normally distributed, the coefficient of determination shows that brand loyalty can explain purchasing decisions by fifty-four percent. At the same time, the rest is influenced by other factors not discussed in the study. Then the regression equation test shows a positive effect of brand loyalty on purchasing decisions and accepts the hypothesis that brand loyalty affects purchasing decisions. It means that brand loyalty for consumers greatly influences them in making purchase decisions, and brand loyalty can be a factor that can make consumers make decisions about purchases.

Keywords: Brand; loyalty; purchase decisions.

Abstrak. Salah satu brand industri kuliner terkenal di Kota Pematangsiantar yaitu Toko Roti Ganda. Terkenalnya brand Toko Roti Ganda menjadikan banyak pengunjung yang berdampak pada kemacetan lalu lintas. Fenomena tersebut disebabkan karena terkenalnya Toko Roti Ganda di masyarakat menjadikan merek yang menjadi prioritas utama masyarakat dibandingkan dengan merek lainnya bagi pengunjung yang datang. Tujuan penelitian ini yaitu untuk mengetahui pengaruh brand loyalty terhadap keputusan pembelian di Toko Roti Ganda. Penelitian ini menggunakan metode kualitatif dan kuantitatif. Terdapat 123 responden yang didapatkan dari populasi penelitian yaitu warga Kota Pematangsiantar dan Kabupaten Simalungun yang pernah melakukan pembelian di Toko Roti Ganda. Hasil koefisien determinasi penelitian ini menunjukkan bahwa brand loyalty berpengaruh terhadap keputusan pembelian sebesar 54\%, sedangkan sisanya dipengaruhi oleh faktor lainnya yang tidak dibahas dalam penelitian ini. Uji persamaan regresi menyatakan brand loyalty berpengaruh positif terhadap keputusan pembelian sehingga hipotesis dapat diterima. Artinya, loyalitas merek bagi konsumen memiliki pengaruh dan dapat menjadi faktor dalam melakukan keputusan pembelian.

Kata Kunci: Brand; loyalty; keputusan pembelian. 


\section{Pendahuluan}

Perkembangan dunia usaha saat ini semakin pesat dan beragam, tidak hanya untuk memenuhi konsep kebutuhan terhadap lidah dan pencernaan, namun industri kuliner juga mampu melengkapi gaya hidup yang sedang berlangsung saat ini (Handayani, 2018), tidak hanya di Indonesia akan tetapi di seluruh dunia (Trihendrawan, 2020) serta kepada dunia usaha mampu mempertahankan kelangsungan hidupnya dengan menghasilkan produk yang memiliki nilai jual yang mampu bersaing dengan produk lainnya. Hal ini diakibatkan oleh para pengusaha yang menghasilkan produk yang begitu dinamis membuat para pelaku pasar atau produsen berlomba dalam memenangkan kompetisi dengan menawarkan produk dalam berbagai merek yang sangat bervariasi (Hadi \& Sumarto, 2010), serta dapat dicapai dengan kreativitas disertai ide segar dalam menciptakan suatu cara atau karakteristik yang memiliki keunikan yang mampu memberikan perhatian dari pelanggan kepada perusahaan yang sering disebut brand (merek) (Pradipta et al., 2016).

Pada kenyataannya merek sering dianggap sebagai identitas yang membedakannya dengan pesaing (Yuliana \& Putra, 2018) karena merek penting untuk pasar konsumen dikarenakan mampu menghubungkan antara konsumen dan perusahaan, kemudian konsumen dapat mengembangkan loyalitas terhadap merek (Lau \& Lee, 1999). Bagi para konsumen perlu untuk mengetahui tentang info-info dari produk yang diminatinya, timbulnya keputusan dalam melakukan pembelian dan bahkan ketika konsumen ingin membeli produk tertentu, merek merupakan faktor yang paling tinggi dalam pengambilan keputusan pembelian (Macdonald \& Sharp, 2000).

Keputusan pembelian dapat dikatakan sebagai respons dari konsumen terhadap produk yang diinginkannya dan memberikan kepuasan kepada pemakainya serta hasil yang memiliki nilai guna yang positif bagi penggunanya. Keputusan pembelian merupakan proses dalam membeli dengan mempertimbangkan dua faktor yaitu orang lain dan situasional (Kotler \& Amstrong, 2012). Munculnya keputusan dalam pembelian tercipta melalui hasil stimulus untuk tetap loyal terhadap merek yang disebabkan peran yang menonjol dari merek tersebut (Nasib \& Bashira, 2019). Seorang konsumen dalam melakukan pembelian telah melakukan analisis apakah suatu produk yang dibeli layak atau tidak untuk dibeli (Hutomo, 2019). Keputusan pembelian adalah suatu konsep perilaku pembelian konsumen dalam memutuskan tindakan pembelian dengan mempertimbangkan manfaat produk maupun jasa (Tundoong \& Mandey, 2014); keputusan pembelian juga dapat menjadi alasan bagaimana konsumen menentukan dalam pemilihan untuk membeli produk yang sesuai dengan kebutuhan, keinginan, dan harapan yang menyebabkan timbulnya rasa puas atau tidak terhadap produk (Puccinelli et al., 2009); dan juga menentukan terhadap produk dan layanannya (Kohli et al., 2004).

Keputusan pembelian dapat dipengaruhi oleh seperangkat aset dari merek dan salah satunya adalah brand loyalty (loyalitas merek) karena brand loyalty memiliki kontribusi dalam menciptakan dan memengaruhi terhadap keputusan pembelian, hal tersebut sejalan dengan penelitian (Zuhdi, 2008) dan (Putri \& Deniza, 2018). Loyalitas merek muncul sejauh mana pelanggan menunjukkan sikap positif dan komitmen terhadap suatu merek, serta berniat membeli suatu merek tersebut di masa depan (Mowen \& Minor, 2002); dan biasanya kecenderungan ini dapat muncul karena konsumen terlebih dahulu memilih merek produk selanjutnya baru memikirkan harga (Sudomo, 2013); dan secara konsep tradisional bahwa loyalitas merek memiliki dimensi tujuan secara kognitif, afektif, perilaku dan membangun merek secara konvensional 
dapat dibangun melalui media massa (Gommans et al., 2001); artinya, media massa dapat digunakan dan memiliki peran besar dalam menciptakan kesan merek dari suatu produk pada konsumen agar selalu mengingatnya.

Loyalitas muncul dari pembelian ulang terhadap produk atau layanan dengan jangka waktu tertentu (Yi \& Jeon, 2003). Selanjutnya loyalitas merek (brand loyalty) dikatakan sebagai kemampuan dari konsumen untuk tetap menggunakan merek yang ditawarkan (Ariestonandri, 2006); dan menjadi ukuran keterikatan konsumen terhadap suatu merek tertentu dengan pikiran yang positif serta konsisten untuk melakukan pembelian di masa mendatang (Nurfitriana et al., 2013); disertai dengan semakin sadarnya para konsumen terhadap merek akan memberikan penilaian yang baik terhadap merek, dan perusahaan dapat menggunakan merek tersebut untuk memengaruhi keputusan dalam melakukan pembelian dari konsumen (Fatmasari, 2018); serta menjadi preferensi dari produk partikel yang terdapat di benak pelanggan atau dikatakan sebagai perilaku pembelian ulang dari pelanggan (Danish et al., 2018); Ketika seseorang membeli produk dan memiliki nama suatu merek itu berarti konsumen tersebut memiliki kesadaran terhadap merek tersebut (Shahid et al., 2017); untuk mendapatkan loyalitas sejati hanya dapat dilakukan dengan penerapan pengukuran loyalitas merek (Bennett et al., 2000); maka dapat disimpulkan bahwa loyalitas dari merek dapat menjadikan konsumen untuk terikat melalui pikiran yang muncul dari benaknya dengan hasil positif serta memberikan penilaian yang baik terhadap produk tersebut.

Kota Pematangsiantar merupakan salah satu kota yang berada di Provinsi Sumatera dan terbesar kedua setelah Kota Medan yang sering menjadi transit dari aktivitas pengunjung (Situmorang \& Suryawan, 2017). Salah satu industri kuliner yang cukup terkenal yaitu Toko Roti Ganda. Usaha Roti Ganda yang memulai usahanya dari tahun 1979 ini merupakan salah satu ikon dari Kota Pematangsiantar (Silaen, 2017). Usaha tersebut berpusat di Jalan Sutomo No. 89, Kelurahan Proklamasi, Kecamatan Siantar Barat. Saat usaha Roti Ganda sudah memiliki cabang yang terletak di Jalan Kartini No. 21 Kelurahan Bantan, Kecamatan Siantar Barat, Kota Pematangsiantar, kemudian Roti Ganda juga sudah ada di Kota Medan, Sumatera Utara. Adapun produk utama yang dihasilkan oleh Toko Roti Ganda yaitu dapat dilihat pada Tabel 1.

Tabel 1. Produk Utama Toko Roti Ganda

\begin{tabular}{lcc}
\hline \multicolumn{1}{c}{ Produk } & Ukuran & Harga( Rp) \\
\hline \multirow{2}{*}{ Roti Tawar } & Besar & $18.000,-$ \\
\cline { 2 - 3 } Selai Srikaya & Kecil & $9.000,-$ \\
\hline & Kecil & $10.000,-$ \\
\cline { 2 - 3 } & $1 / 2$ Kilo & $28.000,-$ \\
\hline
\end{tabular}

Sumber: (Kartika, 2020)

Tabel 1 memperlihatkan bahwa produk utama Toko Roti Ganda terdiri dari roti tawar dan selai srikaya, selain produk utama yang dijabarkan pada Tabel 1, Toko Roti Ganda juga menyediakan roti kelapa, kue basah, dan roti tar (Hindryati, 2020), dan produk dari Roti Ganda tersebut dapat dinikmati oleh kaum muslim dengan aman karena telah memiliki sertifikat halal dari Majelis Ulama Indonesia dengan Nomor Registrasi 0920006620715 (Rahmadani, 2015).

Fenomena yang sering terjadi di Toko Roti Ganda yaitu sesaknya pembeli dan antrian panjang yang disebabkan 
karena kondisi dari ruangan yang kurang luas dan tetap terasa sempit jika banyak konsumen yang berkunjung dan membeli roti tersebut, terlebih pada hari Sabtu, Minggu, dan hari libur keagamaan seperti Idulfitri, Paskah, Natal, serta Tahun Baru (Loo, 2018); masalah yang lain yang ditimbulkannya yaitu kemacetan lalu lintas akibat banyaknya mobil yang parkir di sisi jalan karena lokasinya berada di titik perekonomian (Safana, 2020), hal ini bahkan di masa pandemi Covid-19 pada bulan Desember 2020 pengunjung yang datang dibubarkan gugus tim tugas Covid19 akibat melanggar protokol kesehatan dan banyaknya kerumunan (Metrotv, 2021).

Roti Ganda memang sudah memiliki merek yang terkenal di masyarakat secara umum bahkan seluruh Indonesia, hasil dari wawancara dengan para konsumen yang sering melakukan pembelian di Toko Roti Ganda menyatakan bahwa roti yang dihasilkan terkesan biasa sehingga kurang menarik untuk kalangan usia muda yang lebih mementingkan tampilan. Karena saat ini di Kota Pematangsiantar sudah banyak toko pesaing lainnya yang menjual roti serupa, seperti Franz Bakery, Pitamas, Aroma, dan lainnya, bahkan produk roti tersebut lebih enak rasanya kemudian varian rotinya lebih banyak sehingga menawarkan banyak pilihan yang untuk dibeli. Berdasarkan hasil uraian yang telah dikemukakan sebelumnya, penelitian ini dilakukan untuk mengetahui kemampuan dari brand loyalty dalam memengaruhi keputusan pembelian.

\section{Keputusan Pembelian}

Secara garis besarnya bahwa keputusan untuk melakukan pembelian dapat timbul dari pengambilan keputusan (Foster, 2016), pengambilan keputusan tersebut oleh konsumen berasal dari integrasi yang menggunakan pengetahuan yang dilakukan dalam melakukan evaluasi terhadap dua atau lebih dari perilaku yang dapat menentukan pilihan terhadap salah satu pembelian (Setiadi, 2003).
Tahapan yang dilakukan dalam melakukan pembelian meliputi pengenalan terhadap masalah, melakukan pencarian terhadap informasi, mempertimbangkan alternatif lain dengan melakukan evaluasi, melakukan keputusan terhadap pembelian, dan perilaku yang muncul pascapembelian (Kotler \& Keller, 2009). Dalam melakukan keputusan pembelian menurut Sunyoto (2013) memiliki tujuh komponen keputusan antara lain sebagai berikut.

1) Jenis dari produk, jenis dari produk yang dihasilkan baik itu untuk produk konsumsi maupun produksi serta produk berdasarkan wujudnya (Tiyas, 2021); sebaiknya diperhatikan dalam proses pelaksanan bisnis sebab produk harus mampu dalam mencapai tingkat kualitas yang sesuai dengan fungsi serta penggunaannya, tidak perlu melebihi (Sangadji \& Sopiah, 2013).

2) Bentuk dari produk, bentuk dari produk yang dijual sebaiknya memiliki kualitas dan penampilan yang baik, serta memiliki keunikan sehingga dapat membuat konsumen tertarik untuk membeli (Zulaicha \& Irawati, 2016).

3) Merek produk, merek dari produk akan membuat suatu produk memiliki perbedaan dengan produk yang lain. Kesetiaan dari seorang konsumen terhadap merek terdiri dari proses pengenalan, pilihan serta kepatuhan terhadap merek (Firmansyah, 2019).

4) Penjual dari produk, penjual dari produk merupakan indikator yang mampu menciptakan keputusan pembelian, karena kemampuan dari seorang penjual sering dituntut dalam memengaruhi calon pembeli agar konsumen bersedia membeli produk yang ditawarkan.

5) Jumlah produk, produk yang dihasilkan sebaiknya selalu tersedia ketika ditawarkan kepada konsumen, jumlah dari produk harus diperhatikan dengan keinginan yang timbul dari 
konsumen dengan perkataan lain jangan pernah membuat konsumen kecewa ketika produk yang dicari telah habis di tempat penjualan.

6) Waktu dalam melakukan pembelian, konsumen yang datang sering beragam kehadirannya dalam melakukan pembelian produk, hal tersebut sesuai dengan kebutuhan dan hal yang mendasari konsumen dalam melakukan keputusan pembelian.

7) Cara melakukan pembayaran, prosedur dan mekanisme terhadap pembayaran dari produk atau jasa sesuai dengan ketentuan yang ada. Kemudahan dalam melakukan pembayaran dapat menjadi salah satu bahan pertimbangan dari konsumen dalam melakukan keputusan terhadap pembelian (Purnama et al., 2016).

Faktor yang memengaruhi keputusan pembelian menurut Dharmmesta \& Irawan (2008) dapat berupa pengalaman, sikap dan kepercayaan, konsep diri, kepribadian, budaya, kelas sosial, pengaruh kelompok, dan keluarga. Oleh sebab itu, keputusan pembelian yang dilakukan oleh konsumen cenderung didominasi beberapa faktor yaitu pelayanan, harga, lokasi, dan produk itu sendiri (Sihaloho, 2014).

\section{Brand Loyality}

Loyalitas merek harus dikembangkan dalam semua aspek psikologis agar tidak berubah yang mencakup aspek kognitif, afektif, konatif dan behaviour (Dharmmesta, 1999). Loyalitas merek memiliki tingkatan yang disebut dengan piramida loyalitas. Sebagaimana yang diutarakan oleh Durianto et al. (2001) bahwa tingkatan di dalam loyalitas tersebut terdiri dari pembeli yang senang berpindah, yang bersifat kebiasaan, puas terhadap biaya peralihan, menyukai merek serta memiliki komitmen. Indikator dari loyalitas merek menurut Ballester \& Alemán (2005) secara umum diukur berdasarkan:

1) membeli merek yang sama secara terus-menerus ketika membutuhkannya. Konsumen yang memiliki kesetiaan terhadap merek akan selalu membeli produk dari merek yang sama secara terus menerus dan tidak akan berpindah kepada produk lain ketika konsumen membutuhkan produk tersebut.

2) memberi rekomendasi kepada orang lain, konsumen yang telah menggunakan produk dari suatu merek sudah pasti akan merekomendasikan kepada pihak lain untuk menggunakan produk tersebut, hal ini karena konsumen tersebut telah merasakan hasil dari produk tersebut.

3) kebal terhadap merek lain. Loyalitas kepada suatu merek akan membuat konsumen untuk tetap setia dalam menggunakan produk dari merek tersebut, walaupun muncul merek dari produk lain yang beragam variannya.

4) serta puas dengan manfaat yang diberikan. Loyalitas dari merek produk timbul ketika memberikan kepuasan dan manfaat yang diperoleh dari produk yang digunakan oleh konsumen.

Dengan demikian, konsumen diharapkan menjadi pelanggan yang loyal dan cenderung lebih rendah untuk pindah merek dan menjadi strong word of mouth (Bowen \& Chen, 2001).

Hasil dari teori dan penjelasan dari pendahuluan yang telah dijabarkan, maka kerangka teori penelitian adalah sebagai berikut:

\section{Gambar 1. Kerangka Penelitian}

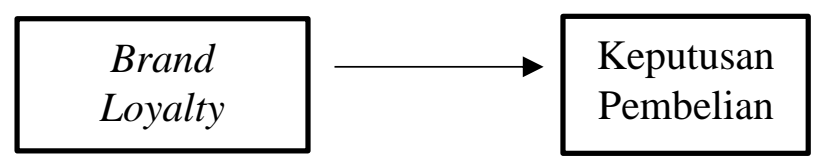




\section{Hipotesis}

Untuk mendapatkan hasil penelitian dari teori yang telah dijelaskan, maka hipotesis dapat dirumuskan sebagai berikut:

$\mathrm{H}_{1} \quad$ : bahwa brand loyalty tidak berpengaruh terhadap keputusan pembelian.

$\mathrm{H}_{2} \quad$ : bahwa brand loyalty berpengaruh terhadap keputusan pembelian.

\section{Metode Penelitian}

Pada penelitian ini menggunakan data primer ataupun sekunder serta survei yang dilakukan dengan pengambilan data langsung ke lapangan. Instrumen penelitian untuk memperoleh data primer dikumpulkan dengan menggunakan kuesioner. Penelitian ini dilakukan kepada masyarakat di Kota Pematangsiantar dan Kabupaten Simalungun yang pernah berkunjung dan berbelanja di Toko Roti Ganda. Jumlah sampel minimal lima kali dari jumlah indikator serta ukuran sampel yang sesuai antara 100-200 responden (Hair et al., 2010). Jumlah sampel yang diperoleh untuk penelitian adalah 123 responden, sehingga syarat minimal responden terpenuhi. Teknik analisis data yang digunakan yaitu uji validitas dengan batas korelasi $\geq 0,30$ (Sugiyono, 2019) dan reliabilitas data (kehandalan) dengan tolak ukur Cronbach's Alpha minimum 0,70 (Eisingerich \& Rubera, 2010), uji koefisien determinasi, normalitas, analisis persamaan regresi sederhana, dan uji hipotesis. Persamaan regresi sederhana tersebut diuraikan sebagai berikut.

$\mathrm{Y}=\mathrm{a}+\mathrm{bX}$.

$\mathrm{Y} \quad$ : Keputusan pembelian

a : Konstanta

b : Koefisien arah dari brand loyalty

$\mathrm{X} \quad$ : Brand loyalty

\section{Hasil dan Pembahasan}

Hasil

\section{Deskripsi Responden}

Pada Tabel 2 berisi profil responden yang diperoleh melalui pengolahan data kuesioner responden yang menjawab kuesioner dapat dilihat pada Tabel 2 berikut.

Tabel 2. Profil Responden

\begin{tabular}{|c|c|c|c|}
\hline Data Responden & Deskripsi Responden & Jumlah & Persentase \\
\hline \multirow{2}{*}{ Jenis Kelamin } & Laki-laki & 32 & $26 \%$ \\
\hline & Perempuan & 91 & $74 \%$ \\
\hline \multirow{4}{*}{ Usia Responden } & $17-25$ & 103 & $84 \%$ \\
\hline & $26-34$ & 7 & $6 \%$ \\
\hline & $35-44$ & 8 & $7 \%$ \\
\hline & $>45$ & 5 & $4 \%$ \\
\hline \multirow{2}{*}{ Domisili Responden } & Pematangsiantar & 74 & $60 \%$ \\
\hline & Simalungun & 49 & $40 \%$ \\
\hline \multirow{5}{*}{ Pekerjaan Responden } & Pelajar/Mahasiswa & 97 & $79 \%$ \\
\hline & ASN/TNI/Polri & 1 & $1 \%$ \\
\hline & Pegawai Swasta & 15 & $12 \%$ \\
\hline & Wira Usaha & 1 & $1 \%$ \\
\hline & dan lainnya & 9 & $7 \%$ \\
\hline \multirow{3}{*}{ Penghasilan Responden } & $<1$ Juta & 94 & $76 \%$ \\
\hline & 1-5 Juta & 26 & $21 \%$ \\
\hline & $>5$ Juta & 3 & $2 \%$ \\
\hline
\end{tabular}

Berdasarkan Tabel 2 menunjukkan bahwa jenis kelamin responden yang paling dominan adalah perempuan dengan jumlah 91 responden (74\%), usia responden penelitian paling banyak adalah umur 17-25 tahun dengan jumlah 103 
responden (84\%), domisili responden yang paling banyak adalah dari kota Pematangsiantar dengan 74 responden $(60 \%)$, pekerjaan responden didominasi oleh pelajar dan mahasiswa dengan jumlah 97 responden (79\%), selanjutnya penghasilan dari responden yang paling banyak adalah di bawah satu juta dengan jumlah 94 responden $(76 \%)$.

\section{Tanggapan Responden}

Tanggapan responden diperoleh melalui pertanyaan yang dilakukan kepada konsumen yang pernah melakukan pembelian di Toko Roti Ganda, untuk lebih jelas mengetahui tanggapan tersebut dapat dilihat pada Tabel 3 berikut.

Tabel 3. Tanggapan Responden

\begin{tabular}{llcc}
\hline \multicolumn{1}{c}{ Tanggapan } & Indikator & Jumlah & Persentase \\
\hline \multirow{2}{*}{ Sarana penunjang (lahan parkir) } & Sangat Luas & 10 & $8 \%$ \\
\cline { 2 - 4 } & Kurang Luas & 113 & $92 \%$ \\
\hline \multirow{2}{*}{ Pembelian yang dilakukan } & Sering membeli & 40 & $33 \%$ \\
\cline { 2 - 4 } & Jarang membeli & 83 & $67 \%$ \\
\cline { 2 - 4 } & Tidak Pernah & 0 & $0 \%$ \\
\hline \multirow{2}{*}{ Lokasi Toko } & Luas & 75 & $61 \%$ \\
\cline { 2 - 4 } & Sempit & 48 & $39 \%$ \\
\hline
\end{tabular}

Pada Tabel 3 dapat dilihat tentang tanggapan responden terhadap keberadaan Toko Roti Ganda yang terdiri dari sarana penunjang, dalam hal ini lahan parkir yang kurang luas dari tanggapan responden yang paling banyak jumlahnya 113 atau $92 \%$, untuk proses pembelian dilakukan responden warga Pematangsiantar dan Simalungun di Toko Roti Ganda paling banyak jawaban adalah jarang melakukan pembelian dengan tanggapan $83(67 \%)$ dengan alasan sudah terbiasa dengan roti tersebut (timbul rasa bosan), dan selalu menimbulkan antrian panjang pada saat berbelanja sehingga menimbulkan rasa kejenuhan, cita rasa yang mulai berkurang sedangkan toko lain menawarkan kualitas yang lebih baik. Pembeli yang sering berkunjung didominasi para pengunjung luar daerah Kota Pematangsiantar dan Simalungun karena Roti Ganda untuk dijadikan oleh-oleh (cendera mata) dalam bentuk kuliner. Lokasi toko dalam melakukan penjualan roti oleh responden dinyatakan luas dengan 75 tanggapan $(61 \%)$.
Hasil tanggapan responden tentang lokasi penelitian yang menyatakan bahwa sarana lahan pakir kurang luas karena pembeli masih mempergunakan parkir umum di tepi jalan dan berlapis (Mistar.ID, 2020), sehingga sering menimbulkan kemacetan lalu lintas jika pengunjung ramai datang membeli pada saat hari libur terutama hari keagamaan, bahkan sampai menggunakan garis polisi saat libur Natal dan Tahun Baru 2021 sehari setelah ramai pengunjung bahkan sampai menimbulkan antrian (Suhendra, 2021).

\section{Uji Validitas}

Uji validitas digunakan untuk mengetahui valid (sah) atau tidaknya suatu kuesioner yang diberikan kepada responden, serta menguji sejauh mana ketepatan atau kebenaran suatu instrumen sebagai alat ukur variabel penelitian. Hasil uji validitas dapat dilihat pada Tabel 4 berikut.

Tabel 4. Uji Validitas

\begin{tabular}{cccc}
\hline Variabel & rhitung & rkritis & Kriteria \\
\hline Brand Loyalty & 0,594 & 0,30 & Valid \\
\hline Keputusan Pembelian & 0,586 & 0,30 & Valid \\
\hline
\end{tabular}


Hasil dari Tabel 4 menunjukkan, hasil pengolahan data bahwa seluruh variabel penelitian dinyatakan valid, hal ini dilihat dari nilai $\mathrm{r}_{\text {hitung }}$ untuk setiap variabel brand loyalty dan keputusan pembelian lebih besar dari ( $>$ ) nilai $\mathrm{r}_{\text {kritis }}$ atau seluruh nilai $r_{\text {hitung }}>$ dari nilai $\mathrm{r}_{\text {kritis }} 0,30$.

\section{Uji Reliabilitas}

Suatu instrumen perlu dilakukan pengujian untuk memperoleh informasi yang dapat dipercaya dalam memperoleh informasi dari alat pengumpulan data, maka perlu dilakukan uji reliabilitas yang hasilnya dapat dilihat pada Tabel 5 berikut.

Tabel 5. Uji Reliabilitas

\begin{tabular}{cccc}
\hline Variabel & rhitung & rkritis & Kriteria \\
\hline Brand Loyalty & 0,815 & 0,70 & Reliabel \\
\hline Keputusan Pembelian & 0,881 & 0,70 & Reliabel \\
\hline
\end{tabular}

Hasil dari Tabel 5 tersebut menunjukkan bahwa seluruh variabel penelitian yaitu brand loyalty dan keputusan pembelian menghasilkan keputusan reliabel karena nilai dari $r_{\text {hitung }}$ dari masing-masing variabel lebih besar dari $r_{\text {kritis, }}$ atau hasil ini didukung dengan nilai dari Cronbach's Alpha hasil pengolahan data menunjukkan hasil $0,8885>0,70$.

\section{Koefisien Determinasi}

Koefisien determinasi dalam penelitian ini digunakan untuk menjelaskan kemampuan dari variabel bebas yaitu brand loyalty untuk menjelaskan variabel terikat keputusan pembelian. Hasil tersebut dijabarkan pada Tabel 6 berikut.

\section{Tabel 6. Koefisien Determinasi}

\begin{tabular}{ccccc}
\hline Model & R & R Square & Adjusted R Square & Std. Error of the Estimate \\
\hline 1 & $.741^{\mathrm{a}}$ &, 549 &, 546 & 5,152 \\
\hline
\end{tabular}

Hasil Tabel 6 menunjukkan bahwa nilai $\mathrm{R}=0,741$ atau $74 \%$ yang berarti terdapat hubungan yang kuat hubungan brand loyalty terhadap keputusan pembelian. Selanjutnya, nilai R Square $=$ 0,549 atau $54 \%$, artinya kemampuan variabel brand loyalty (kesetiaan merek) menjelaskan variabel keputusan pembelian dengan nilai 54\% sedangkan sisanya $46 \%$ dapat dijelaskan oleh faktor lainnya seperti produk, pelayanan mereka dan faktor lain yang tidak menjadi pembahasan dalam penelitian ini.

\section{Uji Normalitas}

Uji normalitas digunakan untuk mengetahui serta menentukan data yang telah terkumpul berdistribusi normal atau diambil dari populasi normal ataukah tidak. Untuk lebih jelasnya dapat dilihat pada tabel 7 berikut.

Tabel 7. Uji Normalitas

\begin{tabular}{llrr}
\hline & & Brand Loyalty & Keputusan Pembelian \\
\hline $\mathrm{N}$ & & 123 & 123 \\
\hline Normal Parameters & & $27, \mathrm{~b}$ & 55,85 \\
\cline { 2 - 4 } & Mean & 28 & 7,644 \\
\cline { 2 - 4 } & Std. Deviation & 4,690 &, 088 \\
\hline Most Extreme & Absolute &, 105 &, 053 \\
\cline { 2 - 4 } Differences & Positive &, 065 &,- 088 \\
\cline { 2 - 4 } & Negative &,- 105 & \\
\hline
\end{tabular}




\begin{tabular}{lrr}
\hline Kolmogorov-Smirnov Z & 1,168 &, 975 \\
\hline Asymp. Sig. (2-tailed) &, 130 &, 297 \\
\hline
\end{tabular}

Tabel 7 memperlihatkan hasil pengolahan nilai pada asymp. sig. (2tailed) untuk brand loyalty atau kesetiaan merek 0,130 dan keputusan pembelian 0,297 yang berarti seluruh variabel penelitian dinyatakan berdistribusi normal, hal ini diukur dengan nilai uji dua arah (asymp. sig. (2-tailed)) lebih besar dari $\alpha 0,05$.

\section{Regresi Sederhana}

Persamaan regresi sederhana digunakan untuk menggambarkan hubungan satu variabel bebas terhadap satu variabel terikat, dan hasil persamaan regresi sederhana tersebut dapat dilihat pada Tabel 8 berikut.

Tabel 8. Uji Persamaan Regresi Sederhana

\begin{tabular}{|c|c|c|c|c|c|c|}
\hline \multirow{2}{*}{\multicolumn{2}{|c|}{ Model }} & \multicolumn{2}{|c|}{$\begin{array}{r}\text { Unstandardized } \\
\text { Coefficients }\end{array}$} & \multirow{2}{*}{$\begin{array}{r}\begin{array}{r}\text { Standardized } \\
\text { Coefficients }\end{array} \\
\text { Beta }\end{array}$} & \multirow[b]{2}{*}{$\mathrm{t}$} & \multirow[b]{2}{*}{ Sig. } \\
\hline & & $\mathrm{B}$ & Std. Error & & & \\
\hline \multirow[t]{2}{*}{1} & (Constant) & 22,883 & 2,753 & & 8,311 & 000 \\
\hline & Brand Loyalty & 1,208 & ,099 & ,741 & 12,146 &, 000 \\
\hline
\end{tabular}

Persamaan regresi sederhana yang ditunjukkan pada Tabel 8 menghasilkan persamaan regresi sederhana $\mathrm{Y}=22,883+$ $1,208 \mathrm{X}$ yang artinya jika konstanta sebesar 22,883 bahwa ketika nilai brand loyalty tidak ada atau 0 , maka nilai keputusan pembelian nilainya 22,883 dan nilai dari koefisien regresi 1,208 yang menjelaskan bahwa ketika penambahan 1 kepada nilai brand loyalty, maka nilai variabel keputusan pembelian bertambah sebesar 1,208. Selanjutnya hasil persamaan tersebut menunjukkan hasil yang positif pengaruh brand loyalty terhadap keputusan pembelian.

\section{Uji Hipotesa (Uji t)}

Hipotesis diperlukan untuk memberikan jawaban sementara terhadap hasil dari penelitian yang dilakukan dapat dilihat pada Tabel 9 berikut.

Tabel 9. Uji Hipotesis (Uji t)

\begin{tabular}{rrrr}
\hline & Model & $\mathbf{t}$ & Sig. \\
\hline \multirow{2}{*}{1} & (Constant) & 8,311 &, 000 \\
\cline { 2 - 4 } & Brand Loyalty & 12,146 &, 000 \\
\hline
\end{tabular}

Penjelasan untuk hipotesis yang dijelaskan pada Tabel 9, memperlihatkan bahwa nilai thitung adalah derajat kebebasan $(\mathrm{df})=(\mathrm{n}-2)=123-2=121$ hasilnya 12,146 dan nilai $t_{\text {tabel }} 1,979$ berarti nilai $t_{\text {hitung }}>t_{\text {tabel }}$ dan nilai Sig $0,000<$ probabilitas 0,05 , maka $\mathrm{H}_{1}$ ditolak dan menerima $\mathrm{H}_{2}$, yang berarti ditemukan pengaruh yang secara nyata (subtansial) variabel brand loyalty terhadap keputusan pembelian.

\section{Pembahasan \\ Pengaruh Brand Loyalty terhadap Keputusan Pembelian}

Perusahaan sangat menginginkan merek produknya dikenal oleh para konsumen, karena dengan merek yang dikenal dengan baik maka masyarakat sebagai konsumen akan mudah mengenal tentang suatu produk dibandingkan merek produk lainnya. Bagi konsumen merek sudah merupakan salah satu faktor yang dapat memengaruhi keputusan pembelian, 
dan biasanya konsumen memiliki suatu bentuk kesetiaan merek kepada produk, konsumen yang loyal kepada merek akan membuat perusahaan bertahan hidup dan loyalitas ini diharapkan mampu menghasilkan keharusan untuk selalu melakukan pembelian.

Penelitian yang dilakukan Ariadi et al. (2019) menyatakan bahwa loyalitas terhadap merek atau brand loyalty memberikan peranan yang sangat penting terhadap keputusan pembelian, kemudian bentuk dari nilai dari brand loyalty dapat memberikan partisipasi yang tinggi kepada keputusan pembelian (Naeem \& Sami, 2020), karena tanpa loyalitas merek terhadap suatu produk maka keputusan pembelian yang hanya didasarkan kepada harga dan kualitas dan tidak memperhatikan suatu branding (Eng \& Keh, 2007). Pendapat Washburn \& Plank (2002) menyatakan bahwa kesetiaan terhadap merek sangat terhubung dan tentunya memengaruhi niat untuk membeli dan loyalitas merek memiliki pengaruh terhadap keputusan pembelian (Akhtar et al., 2016); (Yuliana \& Putra, 2018); (Sucahyo, 2017). Artinya, loyalitas terhadap merek memiliki kemampuan dalam menghasilkan keputusan terhadap pembelian. Akan tetapi pendapat yang berbeda datang dari Hidayati (2018) menyatakan bahwa loyalitas merek dapat berpengaruh positif akan tetapi dapat tidak signifikan karena konsumen adakalanya hanya sekadar membeli karena merek produk tersebut sudah dikenal dengan baik dan sekadar ingin menikmati hasil dari produk tersebut. Demikian juga pendapat Jatmiko \& Setyawati (2015), loyalitas merek tidak memengaruhi keputusan terhadap pembelian, hal ini dapat terjadi ketika produk dari merek tersebut tidak memiliki perubahan atau inovasi, sehingga walaupun merek sudah cukup terkenal ketika produk yang dihasilkan tidak mengalami perubahan dapat membuat konsumen untuk membatalkan pembelian dan berpindah ke merek lain yang memiliki produk yang lebih inovatif dan menarik.

\section{Kesimpulan}

Hasil penelitian menunjukkan bahwa loyalitas merek sangat berpengaruh terhadap keputusan pembelian, hal ini terjadi karena konsumen masih beranggapan bahwa merek dari suatu produk masih memiliki kecenderungan untuk menjamin hasil suatu produk, meskipun sebenarnya suatu merek yang berhasil sering tidak sebanding kualitas produknya. Dan karena keterbatasan baik waktu dan hal lain yang dimiliki penulis maka saran yang dapat diberikan agar Toko Roti Ganda walaupun mereknya sudah terkenal namun untuk kedepannya perlu melakukan pengembangan untuk lokasi usaha yang cukup memberikan kenyamanan kepada masyarakat, misalnya membuka toko baru yang lahan parkirnya cukup luas, sehingga tidak menimbulkan kemacetan atau mengganggu lalu lintas jika konsumen yang datang berkunjung, terutama di hari libur nasional dan hari raya keagamaan.

\section{Daftar Pustaka}

Akhtar, N., Qurat-Ul-Ain., Siddiqi, U. I., Ashraf, A., \& Latif, M. (2016). Impact of a brand equity on consumer purchase decision in l'oreal skincare products. International Review of Management and Business Research, 5(3), 808-816. Diakses dari

\section{https://irmbrjournal.com/papers/146} 7435148.pdf

Ariadi, A., Yusniar, M. W., \& Rifani, A. (2019). Pengaruh brand awareness, brand loyalty, perceived quality, brand image terhadap keputusan pembelian konsumen (Studi konsumen sepeda motor matic honda scoopy pada dealer honda di kota Banjarmasih. Jurnal Wawasan Manajemen, 7(3), 252-268 
Diakses

dari

https://jwm.ulm.ac.id/id/index.php/j wm/article/view/193

Ariestonandri, P. (2006). Marketing research for beginner (panduan praktis riset pemasaran bagi pemula). Yogyakarta: Andi Offset.

Ballester, E. D., \& Alemán, J. L. M. (2005). Does brand trust matter to brand equity?. Journal of Product and Brand Management, 14(3), 187-196. doi: https://doi.org/10.1108/1061042051 $\underline{0601058}$

Bennett, R., Kennedy, J. M., \& Coote, L. V. (2000). Trust, commitment and attitudinal brand loyalty: key constructs in business-to-business relationships. ANZMAC 2000 Visionary Marketing for the 21st Century: Facing the Challenge, January, 88-92. Diakses dari https://www.researchgate.net/profil e/Janet_McColl-

Kennedy/publication/43474088_Tr ust_commitment_and_attitudinal_br and loyalty_Key constructs_in bu siness-to-

business_relationships/links/0c9605 1b0540277a1f000000/Trustcommitment-and-attitudinal-brandloyalty-Key-constructs-in-businessto-business-relationships.pdf

Bowen, J. T., \& Chen, S. L. (2001). The relationship between customer loyalty and customer satisfaction. International Journal of Contemporary Hospitality Management, 13(5), 213-217. doi: https://doi.org/10.1108/0959611011 0395893

Danish, R. Q., Khan, M. K., Ghafoor, M. M., Ahmad, I., Humayon, A. A., \& Aslam, S. (2018). Impact of brand loyalty in assessing purchase intentions of a customer: A study of automobile industry in South Asian perspective. South Asian Studies,
33(2), 347-364. Diakses dari http://pu.edu.pk/images/journal/csas /PDF/3_v33_2_18.pdf

Dharmmesta, B. S. (1999). Loyalitas pelanggan: Sebuah kajian konseptual sebagai panduan bagi peneliti. Jurnal Ekonomi Dan Bisnis Indonesia, 14(3), 73-88. Diakses dari

https://jurnal.ugm.ac.id/jieb/article/ view/39434

Dharmmesta, B. S., \& Irawan. (2008). Manajemen pemasaran modern. Yogyakarta: Liberty.

Durianto, D., Sugiarto., \& Sitinjak, T. (2001). Strategi menaklukkan pasar melalui riset ekuitas dan perilaku merek. Jakarta: Gramedia Pustaka Utama.

Eisingerich, A. B., \& Rubera, G. (2010). Drivers of brand commitment: A cross-national investigation. Journal of International Marketing, 18(2), 64-79.

doi: https://doi.org/10.1509/jimk.18.2.64

Eng, L. L., \& Keh, H. T. (2007). The effects of advertising and brand value on future operating and market performance. Journal of Advertising, 36(4), 91-100. doi: https://doi.org/10.2753/JOA00913367360407

Fatmasari, D. (2018). Pengaruh brand awareness, perceived quality, dan brand loyalty terhadap keputusan pembelian handphone samsung (studi kasus mahasiswa FTIK IAIN Purwokerto). (Skripsi, Institut Agama Islam Negeri Purwokerto, Indonesia). Diakses dari http://repository.iainpurwokerto.ac.i d/4644/

Firmansyah, M. A. (2019). Pemasaran produk dan merek (planning \& strategy). Surabaya: Penerbit Qiara Media. 
Foster, B. (2016). Impact of brand image on purchasing decision on mineral water product "Amidis" (Case study on bintang trading company). American Research Journal of Humanities and Social Sciences, 2(1), 1-11. doi: https://doi.org/10.21694/23787031.16023

Gommans, M., Krishnan, K. S., \& Scheffold, K. B. (2001). From brand loyalty to e-loyalty: A conceptual framework. Journal of Economic and Social Research, 3(1), 43-58. Diakses dari https://markenmanagement.files.wo rdpress.com/2012/01/gommans_fro mbrandloyaltytoeloyalty.pdf

Hadi, P., \& Sumarto. (2010). Pentingnya brand loyalty terhadap minat beli ulang. Jurnal Riset Ekonomi Dan Bisnis, 10(1), 9-18. Diakses dari http://ejournal.upnjatim.ac.id/index. $\mathrm{php} / \mathrm{rebis} / \mathrm{article} / \mathrm{view} / 24$

Hair, J. F., Black, W. C., Babin, B. J., \& Anderson, R. E. (2010). Multivariate data analysis (7th edition). New Jersey: Prentice-Hall.

Handayani, I. (14 September 2018). Tren industri kuliner makin meningkat. Beritasatu.com. Diakses dari https://www.beritasatu.com/gayahidup/510453/tren-industri-kulinermakin-meningkat

Hidayati, A. (2018). Pengaruh brand awareness, brand associations, brand loyalty dan perceived quality terhadap keputusan menabung di BRI syariah Semarang (Studi kasus mahasiswa perbankan syariah Institut Agama Islam Negeri Salatiga). (Skripsi, Institut Agama Islam Negeri Salatiga, Indonesia). Diakses dari http://erepository.perpus.iainsalatiga.ac.id/ 2703/

Hindryati, R. (12 Juni 2020). Menyana roti ganda di Pematangsiantar.
Bisniswisata.co.id. Diakses dari https://bisniswisata.co.id/menyanaroti-ganda-di-pematangsiantar/

Hutomo, D. P. T. (2019). Pengaruh brand equity terhadap keputusan pembelian produk smartphone xiaomi (Survey pada mahasiswa pengguna smartphone xiaomi di lingkungan Fakultas Ekonomi dan Bisnis). (Skripsi, Universitas Muhammadiyah Surakarta, Indonesia). Diakses dari http://eprints.ums.ac.id/79138/

Jatmiko., \& Setyawati, R. L. (2015). Pengaruh brand positioning dan brand equity terhadap keputusan pembelian sepeda motor yamaha. Jurnal Ekonomi Universitas Esa Unggul, 6(02), 18-32. Diakses dari https://ejurnal.esaunggul.ac.id/index .php/Eko/article/view/1526/1393

Kartika, D. (17 Desember 2020). Varian dan info terbaru harga roti ganda khas siantar. Harga.web.id. Diakses dari https://harga.web.id/info-hargavarian-roti-ganda-kuliner-khas$\underline{\text { siantar.info }}$

Kohli, R., Devaraj, S., \& Mahmood, M. A. (2004). Understanding determinants of online consumer satisfaction: A decision process perspective. Journal of Management Information Systems, 21(1), 115-135. Diakses dari

http://www.jstor.org/stable/4039878 $\underline{6}$

Kotler, P., \& Amstrong, G. (2012). Prinsip-prinsip pemasaran (edisi 13). Jakarta: Erlangga.

Kotler, P., \& Keller, K. L. (2009). Manajemen pemasaran (edisi 13). Jakarta: Erlangga.

Lau, G. T., \& Lee, S. H. (1999). Consumers' trust in a brand and the link to brand loyalty. Journal of Market-Focused Management, 4(4), 341-370. doi: 
https://doi.org/10.1023/A:10098865 $\underline{20142}$

Loo, P. (15 Januari 2018). Toko roti ganda, legenda kuliner dari kota P.Siantar. Klayapan.com. Diakses dari

https://www.klayapan.com/tokoroti-ganda-legenda-kuliner/

Macdonald, E. K., \& Sharp, B. M. (2000). Brand awareness effects on consumer decision making for a common, repeat purchase product: A replication. Journal of Business Research, 48(1), 5-15. doi: https://doi.org/10.1016/S01482963(98)00070-8

Metrotv. (2 Januari 2021). Membludak, pengunjung toko roti ganda Pematangsiantar dibubarkan. Metrotvnews.com. Diakses dari https://www.metrotvnews.com/play /kM6CQYaa-membludakpengunjung-toko-roti-gandapematangsiantar-dibubarkan

Mistar.ID. (30 November 2020). Jalan sutomo siantar langganan macet, ini tanggapan kasat lantas. Mistar.ID. Diakses dari https://www.mistar.id/siantar/jalansutomo-siantar-langganan-macetini-tanggapan-kasat-lantas/

Mowen, J. C., \& Minor, M. (2002). Perilaku konsumen (Dwi Kartini Yahya (ed.); Fifth edit). Jakarta: Erlangga.

Naeem, M., \& Sami, A. (2020). Product brand loyalty and purchase decision: a comparative study of automobile industry of Pakistan. International Journal of Entrepreneurial Research, 3(3), 76-87. doi: https://doi.org/10.31580/ijer.v3i3.15 $\underline{04}$

Nasib., \& Bashira. (2019). Pengaruh brand awareness dan loyalitas merek terhadap keputusan pembelian sepeda motor yamaha matic. Jurnal
Manajemen dan Keuangan, 8(1), 3442. https://doi.org/10.33059/jmk.v8i $\underline{1.1137}$

Nurfitriana, A., Wijanarko, B., \& Priyatama, A. N. (2013). Hubungan antara citra merek dan loyalitas merek dengan pengambilan keputusan pembelian body lotion pada mahasiswi Program Studi Psikologi Universitas Sebelas Maret Surakarta. Jurnal Wacana, 5(1), 1$17 . \quad$ Diakses dari https://jurnalwacana.psikologi.fk.un s.ac.id/index.php/wacana/article/vie $\underline{w} / 18$

Pradipta, D., Hidayat, K., \& Sunarti. (2016). Pengaruh brand equity terhadap keputusan pembelian (survei pada konsumen pembeli dan pengguna kartu perdana simpati telkomsel di lingkungan mahasiswa jurusan administrasi bisnis angkatan 2012 \& 2013 Fakultas Ilmu Administrasi Universitas Brawijaya Malang. Jurnal Administrasi Bisnis (JAB), 34(1), 138-147. Diakses dari http://administrasibisnis.studentjour nal.ub.ac.id/index.php/jab/article/vi ew/1327

Puccinelli, N. M., Goodstein, R. C., Grewal, D., Price, R., Raghubir, P., \& Stewart, D. (2009). Customer experience management in retailing: Understanding the buying process. Journal of Retailing, 85(1), 15-30. doi:

https://doi.org/10.1016/j.jretai.2008. $\underline{11.003}$

Purnama, S., Lie, D., Butarbutar, M., \& Thressa, S. I. (2016). Pengaruh harga dan promosi terhadap keputusan pembelian konsumen sepeda motor honda vario techno pada $\mathrm{Cv}$. Teknik Pematangsiantar. Jurnal MAKER, 2(1), 74-82. Diakses dari maker.ac.id/index.php/maker/article /download/40/40 
Putri, S. L., \& Deniza, M. P. (2018). Pengaruh brand awareness dan brand loyalty terhadap keputusan pembelian produk chicken nugget fiesta di kota Padang. Jurnal Agrica, 11(2), 70-78. Diakses dari http://ojs.uma.ac.id/index.php/agric a/article/view/1831

Rahmadani. (11 Oktober 2015). Roti ganda siantar kantongi sertifikat halal MUI. MHM.ASIA. Diakses dari https://mhm.asia/roti-gandasiantar-kantongi-sertika/

Safana, I. (30 November 2020). Kemacetan depan toko roti ganda Siantar jadi masalah yang tak pernah usai. JabarNews.com. Diakses dari https://jabarnews.com/read/95659/k emacetan-depan-toko-roti-gandasiantar-jadi-masalah-yang-takpernah-usai/3

Sangadji, E. M., \& Sopiah. (2013). Prilaku konsumen: pendekatan praktis. Disertasi: himpunan jurnal penelitian. Yogyakarta: Andi.

Silaen, F. (26 November 2017). Roti ganda khas Pematangsiantar. Beritagar.Id. Diakses dari https://beritagar.id/artikel/piknik/roti -ganda-khas-pematangsiantar

Setiadi, N. J. (2003). Perilaku konsumen: konsep dan implikasi untuk strategi dan penelitian pemasaran. Jakarta: Kencana.

Shahid, Z., Hussain, T., \& Zafar, F. (2017). The impact of brand awareness on the consumers' purchase intention. Journal of Accounting \& Marketing, 6(1), 1-4. doi: https://doi.org/10.4172/21689601.1000223

Sihaloho, R. M. (2014). Analisis faktorfaktor yang mempengaruhi perilaku konsumen dalam pengambilan keputusan pembelian produk roti ganda pematangsiantar. (Skripsi, Universitas Sumatera Utara,
Indonesia)

Situmorang, C., \& Suryawan, I. B. (2017). Daya tarik wisata unggulan di daerah transit kota Pematangsiantar, Sumatera Utara. Jurnal Destinasi Pariwisata, 5(1). 170-179. doi: https://doi.org/10.24843/JDEPAR.2 017.v05.i01.p30

Sucahyo, Y. A. (2017). Pengaruh brand association, brand loyalty, brand awareness, dan brand image terhadap brand equity pada brand happy baby. Jurnal Manajemen Dan Start-Up Bisnis, 2(5), 601-610. Diakses dari https://journal.uc.ac.id/index.php/pe rforma/article/view/594

Sudomo, S. (2013). Pengaruh ekuitas merek terhadap keputusan pembelian (Studi kasus konsumen pepsodent di kabupaten Bantul). JBMA Jurnal Bisnis, Manajemen, dan Akuntansi, 1(2), 33-48. Diakses dari

http://jurnal.amaypk.ac.id/index.php /jbma/article/view/13

Sugiyono. (2019). Metode penelitian kuantitatif, kualitatif, dan $R \& D$ (Cetakan-1). Bandung: Alfabeta.

Suhendra, A. (2 Januari 2021). Sehari setelah membludak, toko roti ganda dipasang police line, hanya dibuka 2 pintu untuk pembeli. Metro24jam.com. Diakses dari https://news.metro24jam.com/read/ 2021/01/02/103274/sehari-setelahmembludak-toko-roti-gandadipasang-police-line-hanya-dibuka2-pintu-untuk-pembeli

Sunyoto, D. (2013). Teori, kuesioner \& analisis data: untuk pemasaran dan perilaku konsumen. Yogyakarta: Graha Ilmu.

Tiyas. (20 Maret 2021). Pengertian Produk. Yuksinau.Id. Diakses dari https://www.yuksinau.id/pengertian -produk/ 
Trihendrawan, N. (13 Desember 2020). Industri kuliner berkembang pesat di Indonesia. Sindonews.com. Diakses dari

https://daerah.sindonews.com/read/ 266736/701/industri-kulinerberkembang-pesat-di-indonesia$\underline{1607861534}$

Tundoong, E. K., \& Mandey, S. L. (2014). Kualitas produk dan ekuitas merek pengaruhnya terhadap keputusan pembelian mobil toyota hilux pada PT. Hasjrat Abadi cabang Kotamobagu. Jurnal Riset Ekonomi, Manajemen, Bisnis Dan Akuntansi, 2(2), 1393-1405. Diakses dari https://ejournal.unsrat.ac.id/index.p hp/emba/article/view/4759

Washburn, J. H., \& Plank, R. E. (2002). Measuring brand equity: An evaluation of a consumer-based brand equity scale. Journal of Marketing Theory and Practice, 10(1), 46-62. doi: https://doi.org/10.1080/10696679.2 $\underline{002.11501909}$

Yi, Y., \& Jeon, H. (2003). Effects of loyalty on value perception and brand loyalty. Journal of the Academy of Marketing Science.,
31(3), 229-240. doi: https://doi.org/10.1177/0092070303 253082

Yuliana, Y., \& Putra, M. G. (2018). Pengaruh perceived quality dan brand loyalty terhadap keputusan pembelian pada konsumen sim card. In Seminar Nasional Hasil Penelitian 2018 (Vol. 1 No. 1, pp. 306-312). Diakses dari https://eprosiding.umnaw.ac.id/index.php/p enelitian/article/view/126

Zuhdi, S., \& Yudi, D. (April, 2008). Analisis brand loyalty terhadap keputusan pembelian studi kasus pengguna mobil merek toyota. Jurnal Ilmiah Kesatuan, 10(2), 96105. Diakses dari https://mmulyana.wordpress.com/2 013/01/05/jurnal-ilmiah-kesatuanoktober-2008/

Zulaicha, S., \& Irawati, R. (2016). Pengaruh produk dan harga terhadap keputusan pembelian konsumen di morning bakery Batam. Inovbiz: Jurnal Inovasi Dan Bisnis, 4(2), 125-136. doi: https://doi.org/10.35314/inovbiz.v4i $\underline{2.76}$ 